\title{
European Cohesion Policy
}

\author{
Molle, Willem \\ Londres: Routledge, 2007 \\ ISBN: 0-415-43812-8
}

El debate sobre la política europea de cohesión y sobre el impacto de los fondos estructurales ha crecido de manera exponencial en los últimos años. El paso del tiempo desde la reforma de los fondos estructurales de 1989 ha permitido que florezcan los estudios dedicados a examinar no sólo la razón de ser de la política de cohesión y de los mecanismos que la rigen, sino también los efectos de la misma con objeto de comprobar si se ha progresado en el objetivo de mayor cohesión económica y social establecido en el artículo 158 del Tratado de la Unión Europea. Dos han sido los canales de publicación de estos estudios. Por un lado, los estudios propios de la Comisión Europea -como los siempre útiles informes periódicos sobre cohesión- o los estudios financiados directamente por la Comisión, fundamentalmente, aunque no exclusivamente, por la Dirección General de Política Regional. Por otro, los artículos publicados en revistas científicas por economistas, geógrafos, politólogos y, en menor medida, sociólogos sobre el tema. Frente al primer grupo de estudios, caracterizados, por regla general, por la abundancia de datos y por resultados que, si bien no exentos de críticas, presentan una visión favorable del funcionamiento y del impacto de la política de cohesión europea, los artículos de revistas forman un conjunto amorfo, tanto en lo que se refiere a los temas que tratan, como a los resultados que obtienen: desde visiones abiertamente favorables a los objetivos, métodos y efectos de la política hasta otras claramente críticas.

Esta proliferación de estudios desde distintas perspectivas y disciplinas ha generado una interesante polémica sobre la necesidad, motivación, objetivos, estructura, «gobernanza» e impacto de la política de cohesión que ha redundado en beneficio de la propia política. Pero la pluralidad de enfoques, temas y métodos también ha generado confusión y controversia: mientras que para algunos la política de cohesión es la argamasa que cimenta el proceso de integración europea, para otros no se trata más que, en el mejor de los casos, de una intervención distorsionadora del mercado y, en el peor, de un despilfarro de dinero público en gastos superfluos; mientras que unos consideran que los fondos estructurales y de cohesión han potenciado las bases socioeconómicas de las regiones más vulnerables de la Unión Europea (UE) y fomentado la reducción de las disparidades regionales, otros opinan precisamente lo contrario: que el esfuerzo realizado ha debilitado el potencial de desarrollo de las regiones más pobres de la UE, contribuyendo a crear economías asistidas, cada vez más dependientes de transferencias desde Bruselas. 
Es en este contexto de debate y polémica generado por estudios parciales que nace la necesidad de un libro que, desde un enfoque más holístico, aborde de la A a la $\mathrm{Z}$ todos los aspectos de la política de cohesión europea. De hecho, la ausencia de libros sólidos sobre el tema en los últimos años resultaba curiosa-especialmente en comparación con el número de libros publicados sobre la política agrícola común o las políticas de innovación, por citar algunas- teniendo en cuenta que la política europea de cohesión ha pasado en pocos años de la nada a ser la segunda política por presupuesto de la Unión Europea. El objetivo de European Cohesion Policy de Willem Molle es precisamente intentar cubrir este hueco en el mercado con un libro que, de acuerdo con los objetivos del autor, tenga un enfoque amplio e integrador, una estructura clara, aborde la cuestión de las disparidades territoriales en la UE con un horizonte temporal amplio y desde una visión abierta y crítica, a la par que sirva de referencia para poder profundizar en el estudio de aspectos más concretos relacionados con la cohesión en Europa.

¿Hasta qué punto cumple el libro de Molle estos ambiciosos objetivos? La puntación de European Cohesion Policy en todos estos aspectos es alta. En un ejercicio de síntesis encomiable, Molle genera un manual avanzado que cubre el tema de las políticas de cohesión europea desde todos sus ángulos. Para ello utiliza un ingenioso sistema de capítulos, que él denomina «etapas» que siguen de manera lógica la política de cohesión de la UE, desde la presentación del problema hasta sus resultados y visión de futuro.

En la primera etapa, Molle presenta el problema de la falta de cohesión en Europa desde un ángulo económico, social y territorial y con una perspectiva geográfica amplia que intenta remontarse a tiempos históricos, aunque en gran medida se limite al periodo de los últimos treinta años para el que se tiene información estadística más completa a nivel regional. Este repaso de las disparidades nacionales y regionales desde distintas perspectivas da una visión global de la dimensión de los desequilibrios en Europa, aunque resulta menos efectivo a la hora de identificar el origen de dichos problemas. La segunda etapa trata sobre la necesidad de una política regional. En esta sección Molle se hace las preguntas adecuadas: primero, porqué es necesaria una política de cohesión; segundo, que tipo de política es necesaria; tercero, quién la debe poner en marcha; y finalmente cómo se debe hacer. Precisamente por la simplicidad de esta estructura el capítulo funciona muy bien. Rara vez se encuentra en la literatura sobre el tema una introspección tan sistemática de la motivación de la política de cohesión en Europa. Algunas preguntas, cómo la de por qué la intervención se debe realizar fundamentalmente a nivel regional y no a nivel nacional o local, quedan en el aire, pero esto no es óbice para que el capítulo marque la pauta para el resto del libro.

La tercera etapa lidia con los objetivos y los instrumentos de la política de cohesión europea propiamente dicha. En este estadio Molle divide los objetivos e instrumentos entre aquellos de índole financiera y los de carácter regulatorio y de coordinación, antes de explicar en detalle el proceso de aplicación de la intervención pública en la cuarta etapa. Los tres capítulos que componen estas dos etapas desgranan en detalle y de manera clara los pormenores de los objetivos y el funcionamiento de la política de cohesión y resultan especialmente útiles para todos aquellos que 
quieran acercarse o ponerse al día de manera rápida sobre los entresijos de la intervención europea en el área de desarrollo económico y social.

Una obra de estas características no estaría completa sin la presencia de lo que ha sido el tema estrella de la mayoría de los estudios sobre intervención regional en Europa en los últimos años: la evaluación del impacto de las políticas de desarrollo. Molle subdivide esta etapa entre la evaluación propiamente dicha y la interesante novedad -mucho menos tratada por la literatura hasta ahora- de la consistencia de los objetivos y acciones de las políticas de cohesión con otras políticas de ámbito europeo. El análisis de impacto se fundamenta sobre todo en los resultados de la literatura sobre el tema y no en análisis propios. Esto no debería ser un problema en un libro que, como se indica claramente en la introducción, no tiene más ambición que la de dar una visión general y clara de la política de cohesión europea para estudiantes y profesionales interesados (pág. 2), pero casa mal con el objetivo que Molle se plantea en la página 4, dónde establece que la «esencia» del libro es la de conseguir una mayor claridad en el debate sobre la necesidad y el impacto presente y futuro de las políticas de cohesión. Sin embargo, a la hora de la verdad, Molle prefiere ver los toros desde la barrera, confrontando argumentos positivos y negativos sobre impacto del esfuerzo de cohesión pero sin tomar partido. Quizás este sea mi mayor reproche a lo que es, sin lugar a dudas, un excelente libro. La claridad prometida por Molle en su introducción con respecto al debate sobre el impacto de las políticas regionales no aparece y el lector acaba el libro con la misma duda que lo comenzó. Quizás un meta análisis de las fuentes secundarias consultadas por Molle hubiese ayudado a extraer una visión más diáfana de la capacidad de la política de cohesión europea para cumplir sus objetivos, en general, y del impacto de los fondos estructurales, en particular.

El capítulo dedicado a la consistencia con otras políticas europeas funciona mejor que el de la evaluación del impacto. Molle repasa la relación de la política de cohesión con la política agrícola común, con el proceso de integración hacia el mercado único y con las políticas monetarias, comerciales, de transporte, de medio ambiente y de innovación, haciendo síntesis útiles y claras de los posibles efectos de estas políticas sobre la cohesión económica y social y, sobre todo, de la interacción entre ambos tipos de políticas.

Finalmente, en las conclusiones el autor no sólo mira hacia el futuro, estableciendo una serie de puntos y recomendaciones, sino también allende las fronteras de la UE para ver hasta qué punto la experiencia de europea puede servir de guía para países como Brasil o China, o para organizaciones internacionales, como el MERCOSUR o la ASEAN, con problemas de cohesión similares o mayores. Desgraciadamente, la mayoría de los puntos y recomendaciones no superan el par de párrafos, que sólo sirven para abrir boca, puesto que esbozan una serie de temas de investigación y discusión que podrían haberse desarrollado algo más en el libro.

Pese a los pequeños problemas mencionados en los párrafos anteriores, cada una de las etapas y capítulos de European Cohesion Policy representa una contribución nada desdeñable a nuestro conocimiento de los temas e intervenciones en el campo de la cohesión a nivel europeo. Pero el conjunto del libro representa más que la suma de las partes. El valor añadido del trabajo de Molle recae precisamente en reunir en menos de 350 páginas gran parte del conocimiento sobre los temas de cohesión en 
220 Rodríguez-Pose, A.

Europa. Siguiendo una estructura lógica y con prosa clara, el autor realiza una tarea de síntesis que sólo un investigador experimentado y con enorme experiencia práctica como Molle está en condiciones de hacer. Y lo hace de manera asequible y clara para el que se acerca al tema por primera vez, como para aquellos que, cómo yo, llevamos trabajando ya muchos años sobre él. Esta razón es más que suficiente para recomendar European Cohesion Policy a todos los estudiantes, investigadores y personas interesadas en el porqué, el cómo y en el impacto de la política de cohesión europea, ya que el libro no sólo da una visión general sobre el tema, sino que también contiene la profundidad necesaria para introducir al lector en los principales debates científicos. Disfruté leyendo del libro, lo he recomendado a mis estudiantes del curso de «Crecimiento y Cohesión» en el Colegio de Europa en Brujas y lo recomendaría a todos aquellos que quieran buscar un texto accesible y riguroso sobre el tema.

Andrés Rodríguez-Pose

Departamento de Geografía y Medioambiente

London School of Economics 